\title{
Effects of Chronic $\beta$-Adrenergic Blockade on the Left Ventricular and Cardiocyte Abnormalities of Chronic Canine Mitral Regurgitation
}

\author{
Hiroyuki Tsutsui," Francis G. Spinale," Masayoshi Nagatsu," Phillip G. Schmid,' Kazuaki Ishihara," Gilberto DeFreyte," \\ George Cooper IV, ${ }^{*}$ and Blase A. Carabello*\$ \\ ${ }^{*}$ Cardiology Division, Department of Medicine, Gazes Cardiac Research Institute, and ${ }^{\ddagger}$ Cardiothoracic Division, Department of Surgery, \\ Medical University of South Carolina, Charleston, South Carolina, 29425; ${ }^{8}$ Ralph H. Johnson Department of Veterans Affairs Medical \\ Center, Charleston, South Carolina, 29403; and 'Veterans Affairs Medical Center Department of Internal Medicine, \\ University of Iowa, Iowa City, Iowa, 52246
}

\section{Abstract}

The mechanism by which $\beta$ blockade improves left ventricular dysfunction in various cardiomyopathies has been ascribed to improved contractile function of the myocardium or to improved $\beta$-adrenergic responsiveness. In this study we tested two hypotheses: (a) that chronic $\beta$ blockade would improve the left ventricular dysfunction which develops in mitral regurgitation, and (b) that an important mechanism of this effect would be improved innate contractile function of the myocardium.

Two groups of six dogs with chronic severe mitral regurgitation were studied. After 3 mo both groups had developed similar and significant left ventricular dysfunction. One group was then gradually $\beta$-blocked while the second group continued to be observed without further intervention. In the group that remained unblocked, contractile function remained depressed. However, in the group that received chronic $\beta$ blockade, contractile function improved substantially.

The contractility of cardiocytes isolated from the unblocked hearts and then studied in the absence of $\beta$ receptor stimulation was extremely depressed. However, contractility of cardiocytes isolated from the $\beta$-blocked ventricles was virtually normal. Consistent with these data, myofibrillar density was much higher, $55 \pm 4 \%$ in the $\beta$-blocked group vs. $39 \pm 2 \%(P<0.01)$ in the unblocked group; thus, there were more contractile elements to generate force in the $\beta$-blocked group.

We conclude that chronic $\beta$ blockade improves left ventricular function in chronic experimental mitral regurgitation. This improvement was associated with an improvement in the innate contractile function of isolated cardiocytes, which in turn is associated with an increase in the number of contractile elements. (J. Clin. Invest. 1994. 93:2639-2648.) Key words: mitral valve insufficiency $\bullet$ adrenergic $\beta$ receptor blockaders $\bullet$ ventricular function • left heart failure • congestive hypertrophy

\section{Introduction}

Mechanisms available to the heart for compensating longstanding pressure or volume overload include: $(a)$ the FrankStarling mechanism, $(b)$ the development of myocardial hypertrophy, and $(c) \beta$-adrenergic stimulation. In longstanding se-

Address correspondence to Dr. Blase A. Carabello, Department of Medicine, Medical University of South Carolina, 171 Ashley Avenue, Charleston, SC 29425.

Received for publication 13 October 1993 and in revised form 26 January 1994.

The Journal of Clinical Investigation, Inc.

Volume 93, June 1994, 2639-2648 vere mitral regurgitation, these mechanisms apparently fail because left ventricular myocardial dysfunction eventually develops $(1,2)$. In man and in experimental mitral regurgitation, the contractile deficit is based at least in part on the loss of force-generating elements in individual cardiocytes $(3,4)$. This loss correlates highly with a degree of depression in contractile function in the experimental model (3).

Of the three types of compensatory mechanisms noted above, the development of hypertrophy in mitral regurgitation is modest comnared with that of other volume overloads and compared to pissure overload (5-13). We reasoned that, because it is known that the Frank-Starling mechanism is maximized early in the course of volume overload (14) and since it appears that hypertrophic compensation is limited in mitral regurgitation, a major part of the compensation in mitral regurgitation should be by activation of neurohumoral mechanisms. Indeed, data do show substantial $\beta$-adrenergic support for the failing myocardium in mitral regurgitation (15). Although activation of these mechanisms may provide shortterm benefit (16), long-term $\beta$-adrenergic stimulation may be deleterious. This is implied by the fact that $(a)$ catecholamines reduced the viability and protein synthesis in adult isolated cardiocytes (17) and $(b)$ blocking the $\beta$-adrenergic system has been beneficial in other types of heart failure, improving ejection fraction and survival in patients with left ventricular systolic dysfunction (18-21). The means by which $\beta$ blockade has been effective in restoring contractile performance in those patients is unclear. Three potential mechanisms include $(a) \beta$ blockade-enhanced responsiveness of a depressed $\beta$ receptor adenyl cyclase complex allowing enhanced response to endogenous catecholamines (22-24), (b) protection of the myocardium from the potential toxic effects of prolonged exposure to high levels of circulating catecholamines $(25,26)$ thereby improving innate contractile function, and $(c)$ enhanced myocardial performance secondary to the bradycardia induced by $\beta$ blockade.

This study was performed to test two hypotheses. First, we tested the hypothesis that gradually induced $\beta$ blockade would reverse (at least in part) the contractile dysfunction which develops in chronic experimental mitral regurgitation. Second, we tested the hypothesis that a specific mechanism by which this reversal would occur would be "protection" of the myocardium from the deleterious effects of chronic adrenergic stimulation. We would accept this second hypothesis if we found improvement in the contractile dysfunction of cardiocytes isolated from the myocardium of $\beta$-blocked mitral regurgitation dogs in a milieu free of $\beta$ agonists. In this situation, enhanced $\beta$ receptor responsiveness could not explain improved contractile function, since there would be no $\beta$ receptor stimulation occurring at the time of cardiocyte evaluation. 


\section{Methods}

\section{Study design}

As shown in Fig. 1, two groups of six animals were studied longitudinally from baseline when they were normal through $3 \mathrm{mo}$ of chronic mitral regurgitation when previous experience has demonstrated that contractile dysfunction would be present $(3,27-29)$. At that time, one group of dogs was followed for another 3 mo of chronic mitral regurgitation without further intervention. In the second group, $\beta$ blockade was gradually induced with atenolol after the initial $3 \mathrm{mo}$ of mitral regurgitation and these animals were also followed for 3 mo additionally. Since both groups were followed longitudinally from when they were normal, the animals served as their own controls. Determination of catecholamine levels and in vivo contractile function was performed in both groups at baseline, after 3 mo of chronic mitral regurgitation, and after 6 mo of chronic mitral regurgitation. $1 \mathrm{wk}$ after the 6-mo studies, the animals were humanely killed under deep anesthesia. Isolated viable cardiocytes were disaggregated from the myocardium and studied in vitro $(3,30,31)$ by investigators blinded to the in vivo results. Contractile function of the washed cells were assessed in a milieux free of catecholamines by examination of peak unloaded sarcomere shortening velocity and by examining the viscosity-velocity relationship of these cells (31). Briefly, increasing the viscosity of the milieu of a contracting cardiocyte effectively afterloads the cell; as such the viscosityvelocity relationship of the cardiocyte is analogous to the force-velocity relationship of classic cardiac muscle mechanics.

Additionally, cardiocyte morphometric analysis was performed on a second portion of the myocardium that had been fixed-perfused at the time of removal of the heart.

\section{Assessment of in vivo contractile function}

In vivo contractile function was assessed in these experiments using the mass-corrected slope of the end ejection stress-volume relationship and the end systolic stiffness constant $(28,32,33)$. Although all indexes of in vivo function have their limitations, these two indexes have been investigated extensively by us and by others and their limitations are relatively well known. They have correlated well in the past with an independent standard of contractile function-sarcomere function in isolated cardiocytes (3). The slope of the end ejection stress-volume relationship has been shown to be sensitive to changes in contractile state (27). Because it is also substantially affected by changes in cardiac mass and size (the slope must go down as the heart gets bigger regardless of contractile function) $(34,35)$, we corrected the slope for the mass present at the time of study. Thus as the hearts enlarge reducing the slope, at the same time mass increases and multiplying by mass offsets the decline in slope. We also examined end systolic stiffness which is derived from systolic stress-strain analysis. Since strain is a dimensionless property, this index is independent of size (32); it correlates well with changes in contractile function (32).

Without further intervention, at 6 mo we would have studied one group of dogs during $\beta$ blockade (the chronically blocked group) while the other group would have been studied during full native adrenergic stimulation which could have obscured an in vivo contractile deficit in that group (15). Because of this confounding influence, all determina-

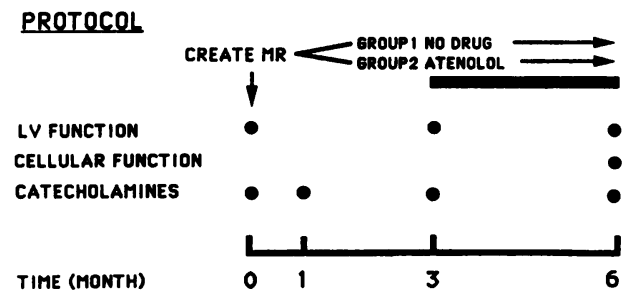

Figure 1. Study protocol. tions of in vivo contractile function at all times of study were performed during acute $\beta$ blockade with esmolol (27-29). In effect, acute $\beta$ blockade "leveled the playing field" for studying contractile function in vivo. Obviously in the chronically blocked group, the addition of the acute $\beta$ blockade would be expected to have no effect. This infusion was administered in the chronically blocked group to confirm that the animals were indeed $\beta$-blocked (by virtue of a lack of change in hemodynamics) and to maintain identical experimental conditions between the two groups.

The data used to construct the indexes of contractile function were obtained from simultaneously recorded pressure and volume data (from which stress could be derived) taken from multiple, variably loaded beats during cineangiography $(27-29,32,33)$. During cineangiography an inferior vena cava balloon which had been inflated was deflated producing a beat by beat increase in both volume and pressure allowing construction of the indexes. The data were obtained as follows. The animals were lightly anesthetized by a combination of droperidol fentanyl given intravenously and inhaled nitrous oxide $\left(\mathrm{N}_{2} \mathrm{O}\right.$ / $\mathrm{O}_{2}$ ratio of 3:1). This combination of anesthetics has been demonstrated to have little effect on contractile function (36). A cutdown was performed over the cervical vessels; the jugular vein and carotid artery were isolated. A Swan-Ganz catheter was introduced into the jugular vein and advanced to the pulmonary artery for the purposes of measuring intracardiac pressures and recording thermodilution forward cardiac output. The inferior vena cava balloon was also inserted into the same vein. A pigtail catheter was advanced to the left ventricle from the carotid artery for the purpose of contrast injection and for recording left ventricular pressure via a mercury-calibrated fluid-filled transducer. An externally calibrated high-fidelity Millar catheter was also inserted through the carotid artery into the left ventricle where it was matched to the mercury-calibrated pressure tracing. Acute $\beta$ blockade was induced by infusion of esmolol $1.5 \mathrm{mg} / \mathrm{kg}$ over $3 \mathrm{~min}$ followed by constant infusion at $0.3 \mathrm{mg} / \mathrm{kg}$ per min for the remainder of the study. After $\beta$ blockade was accomplished, a left ventriculogram was performed in the $30^{\circ}$ right anterior oblique projection using nonionic contrast media. This ventriculogram was used to calculate cardiac volumes, mass, and ejection fraction. After a 15 -min recovery period, a "contractility" ventriculogram was performed using the inferior vena cava balloon to vary pressure and volume as described above to develop the contractile indexes.

These procedures were followed identically in every animal at each of the three observation periods. In the initial study, mitral regurgitation was then created. In the acute studies and those at 3 and 6 mo of mitral regurgitation, the catheters were then withdrawn, the vessels repaired and the animals recovered under veterinarian supervision. Animals were observed daily for signs of heart failure and heart rate was recorded twice weekly. At all times the standard of care of the animals met or exceeded those of the American Physiologic Society and the American Association for Accreditation of Laboratory Animal Care.

\section{Creation of mitral regurgitation}

Mitral regurgitation was created using the closed-chest chordal rupture technique which we have previously described (27-29, 37). Briefly, a 7-French $30-\mathrm{cm}$ sheath is inserted into the carotid artery and advanced across the aortic valve. A urologic calculus grasping forceps is then introduced into the sheath and manipulated to engage and rupture chordae tendineae in a sequential fashion. Only a few chords need to be ruptured to create severe mitral regurgitation. Thus the bulk of the mitral apparatus remains intact even after mitral regurgitation is created. After each chordal rupture, wedge pressure, aortic pressure, pulse rate, and forward stroke volume are assessed. When pulmonary capillary wedge pressure rises to $20 \mathrm{mmHg}$ or forward stroke volume is reduced to $50 \%$ of its baseline value, the mitral regurgitation is severe. This is confirmed by performing a left ventriculogram from which the amount of regurgitation can be assessed qualitatively and from which regurgitant fraction is derived to more precisely quantitate the amount of mitral regurgitation. 


\section{Chronic $\beta$ blockade}

Chronic $\beta$ blockade was induced by the administration of oral atenolol in gradual increments. Starting with $12.5 \mathrm{mg}$ daily the dose was increased by $12.5 \mathrm{mg}$ every $2 \mathrm{wk}$ until a total dose of $50 \mathrm{mg}$ per day was given. The effectiveness of $\beta$ blockade was then tested by infusion of isoproterenol at a dose of $4.0 \mu \mathrm{g} / \mathrm{kg}$ per min. In every case this dose of isoproterenol failed to increase heart rate by more than five beats per minute indicating near-total $\beta$ blockade. The presence of $\beta$ blockade was further proven in the atenolol group when the acute infusion of esmolol during the 6-mo in vivo study failed to lower heart rate or cardiac output in any animal receiving chronic $\beta$ blockade.

We are aware that the canine myocardium contains both $\beta_{1}$ and $\beta_{2}$ receptors. In human heart failure, $\beta_{2}$ receptors become relatively more prevalent because their number stays constant while $\beta_{1}$ receptors are decreased (38) and this might also occur in dogs. Although one could argue that it might have been wise to block both types of receptors, we chose the $\beta_{1}$ selective drug, atenolol, for hemodynamic reasons. Because this drug does not block $\beta_{2}$ receptors peripherally, it tends not to increase total peripheral resistance which would worsen the amount of mitral regurgitation, thereby changing the quality of the primary condition being studied.

\section{Determination of catecholamine concentrations}

$10 \mathrm{ml}$ of blood was collected, centrifuged at $10,000 \mathrm{rpm}, 4^{\circ} \mathrm{C}$ for $5 \mathrm{~min}$, and $2 \mathrm{ml}$ of plasma was saved and stored $-70^{\circ} \mathrm{C}$ until assayed. Plasma norepinephrine was analyzed by radioenzymatic assay using a commercial kit for determination of catecholamines (CAT-A KIT, Amersham Corp., Arlington Heights, IL). Norepinephrine was converted to its meta- $\left[{ }^{3} \mathrm{H}\right]$-methoxy derivatives, i.e., catechol- $O$-methyl transferase ion the presence of $\left[{ }^{3} \mathrm{H}\right]$ methionine, extracted and separated by thinlayer chromatography. The derivative, $\left[{ }^{3} \mathrm{H}\right]$ noremetanephrine was further converted to $\left[{ }^{3} \mathrm{H}\right]$ vanillin by periodate oxidation and $\beta$ radioactivity was determined by liquid scintillation counting (39).

\section{Contractile function of cardiocytes studied in vitro}

$1 \mathrm{wk}$ after the final determination of in vivo contractile function, the animals were deeply anesthetized. After a thoracotomy was performed, the hearts were removed quickly and placed in a calcium-free buffer of the following composition (mM): $\mathrm{NaCl} 130.0, \mathrm{KCl} 4.8, \mathrm{MgSO}_{4} 1.2$, $\mathrm{NaH}_{2} \mathrm{PO}_{4} 1.2, \mathrm{NaHCO}_{3} 2.5$, Hepes buffer 12.0, and glucose 12.5; 6 $\mathrm{mg} /$ liter insulin was also added. The atria and great vessels were next removed, leaving the left circumflex coronary artery intact. A wedge of left ventricular free wall perfused by either the first or second branch of this artery was then dissected free of the heart, the arterial branch was cannulated, and the specimen was cleared of blood by brief perfusion with buffer warmed to $37^{\circ} \mathrm{C}$ and gassed with $100 \% \mathrm{O}_{2}$. To dissociate the cardiocytes from the tissue, perfusion was continued for $15 \mathrm{~min}$ at $37^{\circ} \mathrm{C}$ by recirculating the buffer, now supplemented with $155 \mathrm{U} / \mathrm{ml}$ type II collagenase and $10 \mu \mathrm{M} \mathrm{Ca}^{2+}$; mean pressure $(\sim 80 \mathrm{mmHg})$ and $\mathrm{pH}(\sim 7.40)$ were kept within the physiological range. Any undissociated portions of the specimen, primarily the borders and epicardium, were then discarded. The remaining collagenase-perfused tissue was placed in fresh enzyme-containing buffer, to which was added $3 \%$ saltfree bovine serum albumin and $300 \mu \mathrm{M} \mathrm{Ca}^{2+}$, and minced into $\sim 2$ $\mathrm{mm}$ cubes. The minced tissue was then gently agitated for $5 \mathrm{~min}$ at $37^{\circ} \mathrm{C}$ while being gassed with $100 \% \mathrm{O}_{2}$. The cardiocytes were harvested by drawing off the supernatant in which they were suspended for filtration through $210-\mu \mathrm{m}$ nylon mesh. They were kept for $1 \mathrm{~h}$ at $37^{\circ} \mathrm{C}$ and pH 7.4 in collagenase-free buffer supplemented with $2.5 \mathrm{mM} \mathrm{Ca}^{2+}$ before defining contractile function.

The use of laser diffraction techniques for measuring sarcomere motion in isolated cardiocytes is well established $(40,41)$. An aliquot of isolated cardiocytes was added to $4 \mathrm{ml}$ of the $2.5 \mathrm{mM} \mathrm{Ca}^{2+}$ buffer in a well affixed to a glass slide. The cardiocytes came to rest on the bottom of this chamber, which was placed on the stage of an inverted microscope. The buffer was kept at $37 \pm 0.1^{\circ} \mathrm{C}$ by a thermostated heating stage. The cardiocytes were stimulated to contract between platinum wire electrodes by $0.25 \mathrm{~Hz}, 100-\mu \mathrm{A} \mathrm{DC}$ pulses of alternating polarity. Changes in sarcomere length were measured from movement of the first-order diffraction pattern cast by substage laser light passing through the sarcomeres of a given cardiocyte onto diametrically opposed optical sensors situated above the microscope stage.

Inclusion of methylcellulose in the cardiocyte superfusate was used to impose graded external loads on the cells during contraction, as we have described in detail before (31). Briefly, $2 \%$ solutions of methylcellulose of increasing polymer length were prepared in the standard 2.5 $\mathrm{mM} \mathrm{Ca}{ }^{2+}$ buffer. The viscosity of each methylcellulose solution was measured at $37^{\circ} \mathrm{C}$ by both a Brookfield viscometer and by falling ball viscometry (42); the two techniques produced identical results. To be sure that contractile function $(43,44)$ and morphology $(45)$ were not affected by potential osmotic changes in the viscous solutions, the osmolarity of each methylcellulose solution was measured by both equilibrium vapor pressure and freezing-point depression. The osmolarity of the standard buffer was $290 \pm 5 \mathrm{mosM} / \mathrm{kg}$, and as would be expected for $2 \%$ solutions of very large molecules, this value did not increase significantly in any of the methylcellulose solutions.

Sarcomere motion was characterized as described before (31). The cardiocytes (five left ventricular cells from each of seven control dogs and five left ventricular cells from each of 10 mitral regurgitation dogs) were stimulated to contract at $0.25 \mathrm{~Hz}$ either in the standard 1-centipoise buffer or in buffer-methylcellulose solutions of known viscosities ranging from 12 to 500 centipoise. When the extent of shortening was stable after 10-15 contractions, 10 contractions were sampled and averaged to yield a final profile of sarcomere length and velocity versus time during contraction. Only cardiocytes with the following characteristics were analyzed: single, rod-shaped cells unattached to adjacent cells, which contracted with each stimulus and were quiescent between stimuli. To apply a viscous load to contracting cardiocytes, the cells were immersed in superfusates of differing viscosities. Superfusate viscosities (at $37^{\circ} \mathrm{C}$ ) of $1,12,160$, and 500 centipoise were used in studying the cardiocytes from each left ventricle; they were applied in random sequence to prevent any systematic sampling bias, and each cell was studied at all four viscosities.

\section{Morphometric analysis}

A region of the left ventricular free wall $(8 \times 8 \mathrm{~cm})$ was perfused via the anterior descending artery with a buffered sodium cacodylate solution containing $2 \%$ paraformaldehyde, $2 \%$ glutaraldehyde solution ( $\mathrm{pH} 7.4$, $325 \mathrm{mosM}$ ) for $20 \mathrm{~min}$ using a perfusion pressure of $100 \mathrm{~mm} \mathrm{Hg} \mathrm{(46).}$ After perfusion, this region was finely minced, placed in additional fixative for $3 \mathrm{~h}$, and then prepared for electron microscopy. From the remainder of the left ventricular free wall, three full-thickness sections $(2 \times 2 \mathrm{~cm})$ were taken, immersed in $10 \%$ buffered formalin for $3 \mathrm{~h}$, and prepared for light microscopic examination.

Light microscopy. The tissue was processed for light microscopic examination through graded ethanols, cleared in xylenes, and embedded in paraplast. Slices $4 \mu \mathrm{m}$ in thickness were cut from the blocks and mounted on glass slides and stained with hematoxylin and eosin for morphometric analysis. These sections were mounted on an inverted microscope (IM-35, Ziess, Munich, Germany) and circumferentially oriented cardiocytes were imaged using an epiflorescence illuminator with a rhodamine filter at a magnification of $630 \times(46,47)$. By using this approach, cardiocyte diameter could be determined in situ and used for subsequent cardiocyte volume computations. Three slices at 1 , 2 , and $3 \mathrm{~mm}$ deep from within each tissue block were examined. By using this method, nine full-thickness sections from the left ventricle of each animal were examined.

Left ventricular sections from the present study were also prepared in order to examine the morphology of the capillary bed. Recent reports have shown that histochemical staining with the lectin Griffonia simplicifolia $\left(\mathrm{GSA}-\mathrm{B}_{4}\right)$ is a sensitive and reliable method to visualize the entire capillary vasculature within skeletal and cardiac muscle (48, 49). Accordingly, left ventricular sections were stained with this lectin 
and the capillary density within the myocardium was determined as previously described $(8,49)$. The lectin (Sigma Chemical Co., St. Louis, MO) conjugated to horseradish peroxidase was incubated on the tissue sections as described previously. The stained left ventricular sections containing circumferentially oriented capillaries were imaged at a final magnification of $400 \times$. For each left ventricular section, 10 random fields with an area $25,390 \mu \mathrm{m}^{2}$ per field were analyzed. By using computer aided stereology, the number of capillaries per unit area (numerical density) within the myocardial sample was computed as previously described (48-50).

Electron microscopy. Tissue sections were prepared for electron microscopy using methods described by this laboratory previously (46, 47). Six tissue blocks in the circumferential orientation from the left ventricle of each dog were then used to obtain thin sections for electron microscopy. Three grids, containing three thin sections each, were prepared from each block. Thin sections were stained with uranyl acetate and lead citrate and examined with a model $100 \mathrm{~S}$ electron microscope (JEOL USA, Peabody, MA). The central portion of each section was photographed at a calibrated magnification of 10,000 . These electron micrographs were then coded and this code was not broken until the completion of the study. From the circumferentially oriented micrographs, the percent volume of myofibrils within cardiocytes was analyzed morphometrically by using a stereology sampling grid consisting of 140 sampling points (46-48).

Regional variability of the percent volume of myofibrils was also studied in two dogs with mitral regurgitation not receiving $\beta$ blockade. We felt that since the pathology would be the most disordered in these dogs, variability would be greater here. Samples were taken from the apex, midwall, and base from both the endocardium and epicardium for comparison.

The total left ventricular myocardial volume was computed by dividing left ventricular weight by the specific gravity of muscle tissue: $1.06 \mathrm{~g} / \mathrm{ml}(46,51)$. The total volume of left ventricular myofibrils was computed as the product of total myocardial volume and the percent volume of myofibrils. Total mitochondrial volume was computed in identical fashion.

Cardiocyte examination. Cardiocytes were isolated by using methods described above $(3,30)$. Isolated cells $\left(5 \times 10^{4}\right.$ cells $\left./ \mathrm{ml}\right)$ were then immediately transferred into electron microscopy fixative solution. The isolated cardiocytes were imaged using $\mathrm{a} \times 10$ phase contrast objective. The image was input into the image analysis system and the images were digitized at $512 \times 512$ line resolution and 256 gray levels. Individual cell profiles were automatically discriminated by gray level in order to determine cardiocyte length, width, and profile surface area $(46,47)$. The volume of the digitized cardiocyte profile was then computed using methods previously described $(46,52)$. Briefly, the cardiocyte was digitally sectioned into $1-\mu \mathrm{m}$ increments perpendicular to the long axis of the cell. The volume of each of these segments was then computed based upon a cylindrical frame of reference. Total cardiocyte volumes were estimated as the sum of these individual volumes of rotation about the long axis of the cell and also by using the average cell diameter obtained from the myocardial sections analyzed $(46,52)$. From this computed isolated cardiocyte volume, the cardiocyte myofibril and mitochondrial volumes were determined using the volume percent of myofibrils and mitochondria determined from the electron microscopic examination.

\section{Calculations}

Volumes were determined using the area length method. Left ventricular mass was determined using Rackley's method (53), previously demonstrated to be accurate as used in our laboratory (27). Wall stress $(\sigma)$ was calculated from Mirsky's formula (54). The end systolic stiffness constant, $k$, was determined by solving the equation

$\sigma=C \mathrm{e}^{k \ln (1 / H)}$

for $k$, where $C$ is a constant, and the natural logarithm of $1 / H$ (the inverse of wall thickness) is the strain term in this stress strain analysis of systolic stiffness (32). The slope of the end ejection-stress volume relationship was determined by linear regression. As in previous studies, we used end ejection volume matched to end systolic pressure. Although end ejection and end systole are not synonymous in mitral regurgitation, we have used end ejection volume because $(a)$ it is clearly definable, $(b)$ little ejection occurs after aortic valve closure in mitral regurgitation, and $(c)$ these data have correlated well to the more laborious isochronally derived $E_{\max }$ values in previous studies (28). Regurgitant fraction $(R F)$ was defined as:

$R F=\frac{S V_{\mathrm{t}}-S V_{\mathrm{F}}}{S V_{\mathrm{t}}}$

where $S V_{\mathrm{t}}=$ total stroke volume (angiographic end diastolic volume - end systolic volume) and $S V_{F}=$ forward stroke volume (thermodilution cardiac output/heart rate).

\section{Statistics}

Data are expressed as mean \pm 1 SE. Differences between groups and differences between parameters studied at different time points within the same group were inferred by two-way analysis of variance followed by a Newman-Keuls test if ANOVA testing demonstrated that differences were present.

\section{Results}

Heart rate in the conscious state at baseline was $91 \pm 5$ beats/ min in the unblocked group and $92 \pm 6$ beats/min in the group that eventually received $\beta$ blockade. After 3 mo of mitral regurgitation, heart rate had increased similarly in both groups ( $138 \pm 6$ beats/min in the unblocked group, $137 \pm 6$ beats $/ \mathrm{min}$ in the eventually blocked group). After $\beta$ blockade was instituted, heart rate fell significantly, $119 \pm 4$ beats/min once atenolol reached its maximum dose, whereas heart rate was unchanged, $136 \pm 5$ in the unblocked group $(P<0.05)$. Before the institution of $\beta$ blockade after 3 mo of mitral regurgitation, all animals in both groups manifested tachypnea as a sign of heart failure during at least an observation period. After institution of atenolol in the $\beta$ blockade group, this sign was no longer detected in five of the six dogs.

Fig. 2 demonstrates that severe mitral regurgitation was created and maintained in both groups of dogs as indicated by

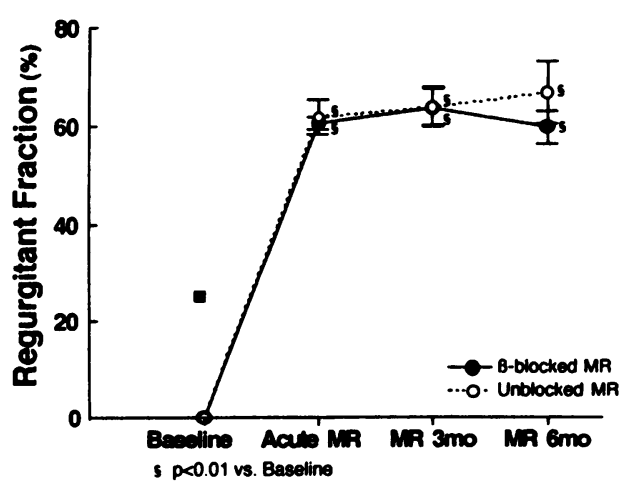

Figure 2. Regurgitant fraction for both groups is demonstrated over the time course of the study. Both groups had a similar magnitude of regurgitation and thus a similar magnitude of volume overload. MR, mitral regurgitation; $\beta$-blocked MR, the group receiving atenolol; unblocked MR, the group of dogs with mitral regurgitation that did not receive atenolol. 


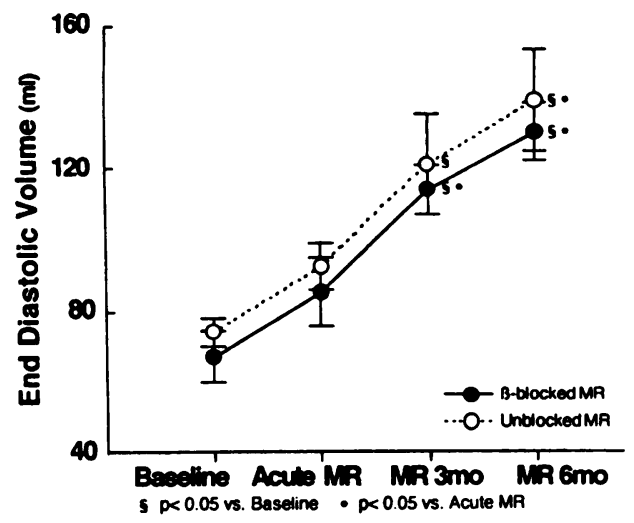

Figure 3. End diastolic volume is shown for both groups throughout the study. In both groups, end diastolic volume nearly doubled. There were no differences between groups at any time period. The abbreviations are the same as in Fig. 2.

regurgitant fraction of $60 \%$. Thus, both groups of dogs experienced similar severe volume overload. Fig. 3 demonstrates that this similar volume overload produced a similar increase in end diastolic volume which increased in the unblocked group from $74 \pm 3 \mathrm{ml}$ to $139 \pm 14 \mathrm{ml}$ after $6 \mathrm{mo}$ and increased from $71 \pm 7$ to $127 \pm 9 \mathrm{ml}$ in the $\beta$-blocked group.

As a prerequisite for supposing that adrenergic overstimulation might cause left ventricular dysfunction, it had to be demonstrated that catecholamines were elevated. Fig. 4 demonstrates norepinephrine levels in the two groups of dogs. In both groups, plasma norepinephrine increased significantly and by $>100 \%$.

Fig. 5 demonstrates left ventricular mass normalized to body weight for the two groups. After 3 mo of mitral regurgitation, the left ventricular to body weight ratio increased similarly by $\sim 45 \%$. However, in the unblocked group of dogs with mitral regurgitation, this ratio plateaued and did not increase further. Conversely, in the $\beta$-blocked group LVBW continued to increase such that it was significantly higher at 6 mo than it had been at $3 \mathrm{mo}(5.04 \pm 0.36,3 \mathrm{mo}$ vs. $6.18 \pm 0.48,6 \mathrm{mo}, P$

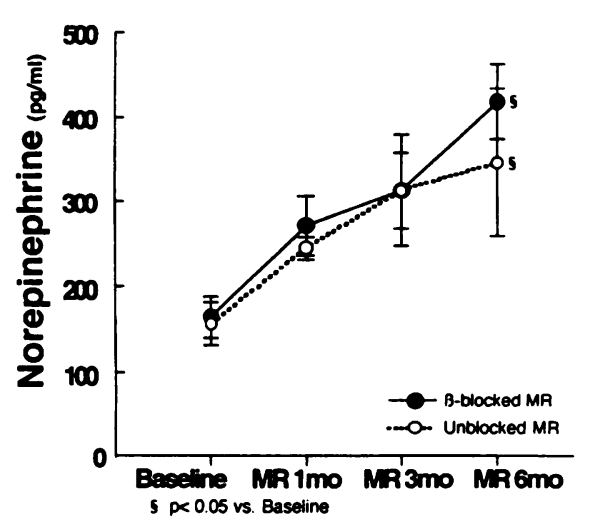

Figure 4. Norepinephrine levels are shown for both groups during the time course of the study. In both groups, norepinephrine was significantly increased after 6 mo consistent with a hypothesis that there was increased $\beta$-adrenergic stimulation. The abbreviations are the same as in Fig. 2.

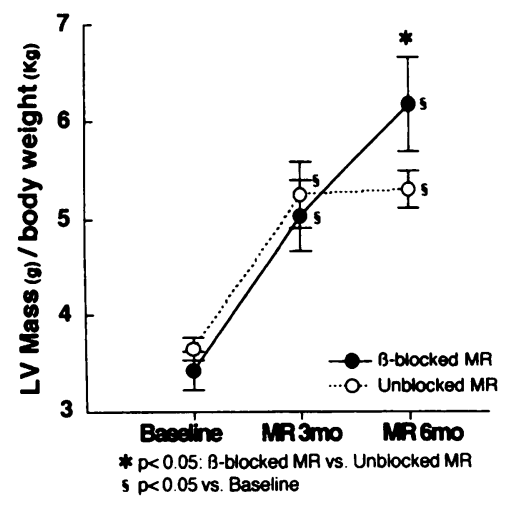

Figure 5. Left ventricular (LV) mass indexed to body weight as a ratio is demonstrated. In both groups, left ventricular mass increased significantly and similarly after 3 mo of mitral regurgitation. In the unblocked group, there was no further increase from 3 to $6 \mathrm{mo}$; however, in the group receiving atenolol, mass increased significantly such that it was greater than the unblocked group after 6 mo.

$<0.05$ ) and also was significantly higher than that of the unblocked group. Body weight did not change in either group during the study. Fig. 6 demonstrates changes in pulmonary capillary wedge pressure. It was similarly elevated in both groups after $3 \mathrm{mo}$ of mitral regurgitation. However, it then fell significantly at $6 \mathrm{mo}$ in the $\beta$-blocked group while no reduction occurred in the unblocked group. Fig. 7 demonstrates the changes in two indexes of contractile function. Both were similarly and severely depressed after 3 mo of chronic mitral regurgitation. In the unblocked group this depression persisted for the next $3 \mathrm{mo}$. However, in the group that received atenolol, there was substantial improvement in both indexes compared to 3 mo of mitral regurgitation and compared to the unblocked group. While mass-corrected end ejection stress-volume relationship was still mildly depressed in the $\beta$-blocked group compared to baseline, end systolic stiffness $(k)$ returned to the baseline value. Contractility data from the isolated cardiocytes are shown in Fig. 8. There was an excellent correlation between the in vivo index of contractile function (end systolic stiffness, $k$ ) and unloaded sarcomere shortening velocity. With one excep-

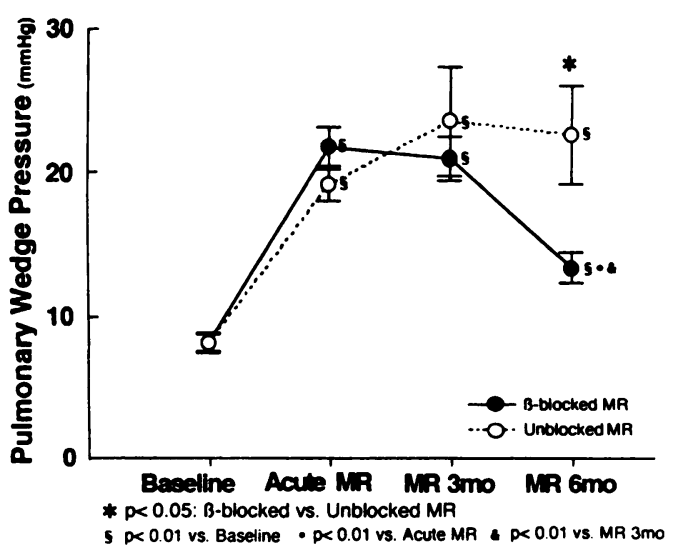

Figure 6. Pulmonary wedge pressure is demonstrated for both groups during the time course of the study. It was significantly elevated to a similar degree after 3 mo of mitral regurgitation. In the group receiving atenolol, wedge pressure then fell significantly from the 3 rd to the 6 th mo. 

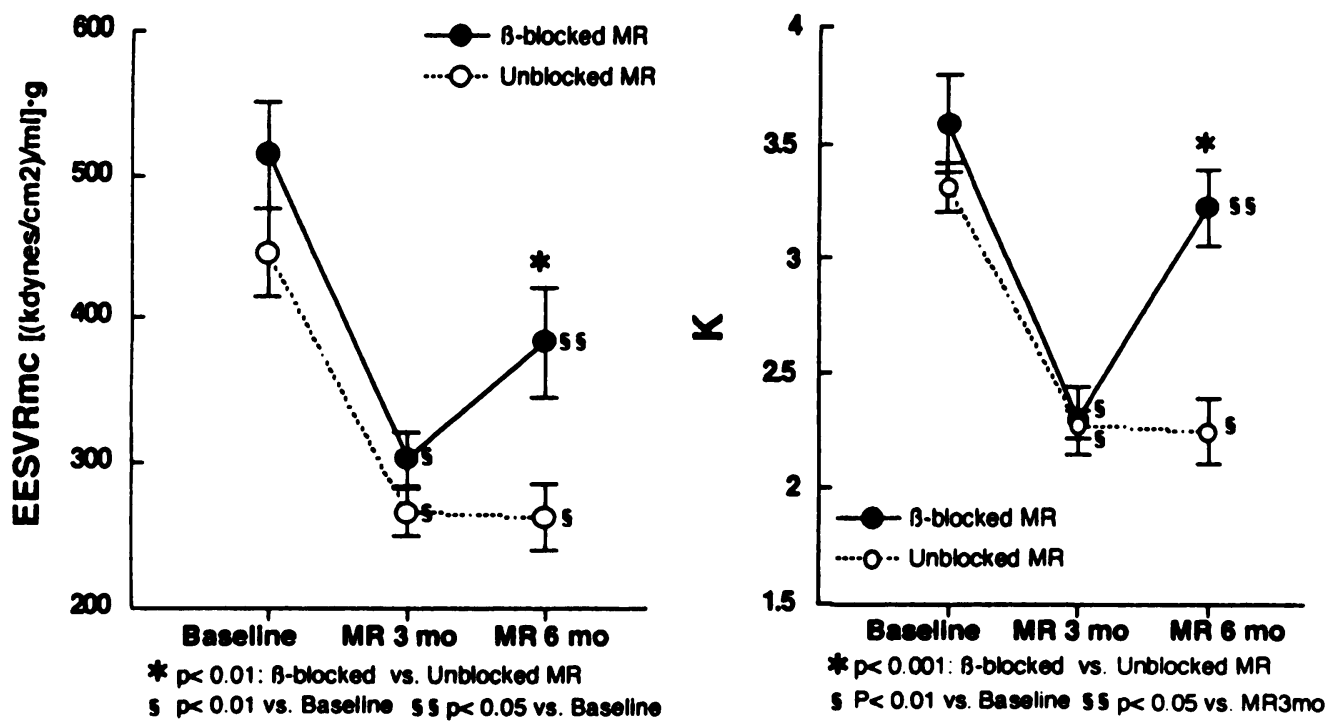

Figure 7. Two indexes of contractile function (left panel-slope of the end ejection stress-volume relationship corrected for mass, EESVRmc; right panel-end systolic stiffness constant, $K$ ) are shown. Both indexes demonstrate a severe fall in contractile function after 3 mo of mitral regurgitation. Contractile function remained depressed in the unblocked group while the group receiving atenolol improved significantly. In fact, end systolic stiffness returned entirely to normal.

tion the $\beta$-blocked dogs fell upward and to the right of the unblocked dogs demonstrating improved contractile function compared to the unblocked group, both in vivo and in vitro. In the right hand panel of this figure, the cardiocyte velocity-viscosity relationship is demonstrated for normal dogs, for the $\beta$-blocked mitral regurgitation dogs and for the unblocked mitral regurgitation dogs. The cardiocytes from the $\beta$-blocked mitral regurgitation dogs were slightly depressed compared to those from normal dogs only in the unloaded state. At other viscosities contractile function was similar to cells from normal dogs. However, the sarcomere shortening velocity of cardiocytes from the unblocked dogs was depressed at all viscosity levels except for $500 \mathrm{cps}$.

Cardiocyte morphometric data are demonstrated in Table I. Cardiocyte length was increased in both mitral regurgitation groups. Capillary density was not reduced consistent with previous work demonstrating normal coronary blood flow and flow reserve in this model (29). Importantly, the percentage of the cell comprised by myofibrils was reduced from $64 \pm 2 \%$ in normals to $39 \pm 2 \%$ in the unblocked group $(P<0.05)$. The magnitude of this reduction was consistent between the endo- cardium and epicardium and among sections taken from the base, midwall, and apex. In the $\beta$-blocked group, there was a substantial increase in the percentage of the cell comprised by myofibrils to $55 \pm 4 \%(P<0.05)$. Improvement in myocardial architecture can be seen in Fig. 9.

\section{Discussion}

There were three major findings of this study. First, $\beta$ blockade substantially ameliorated the contractile dysfunction caused by chronic experimental mitral regurgitation. To our knowledge this is the first time that $\beta$ blockade has been demonstrated to be efficacious in the treatment of contractile dysfunction due to valvular heart disease. Second, we demonstrated that at least one mechanism by which restoration in contractile function occurred was improvement in the function of isolated cardiocytes. This occurred in the absence of $\beta$ receptor stimulation. Improvement in cardiocyte function in the absence of $\beta$ stimulation indicates that chronic $\beta$ blockade must have produced a fundamental improvement in innate cardiocyte contractility
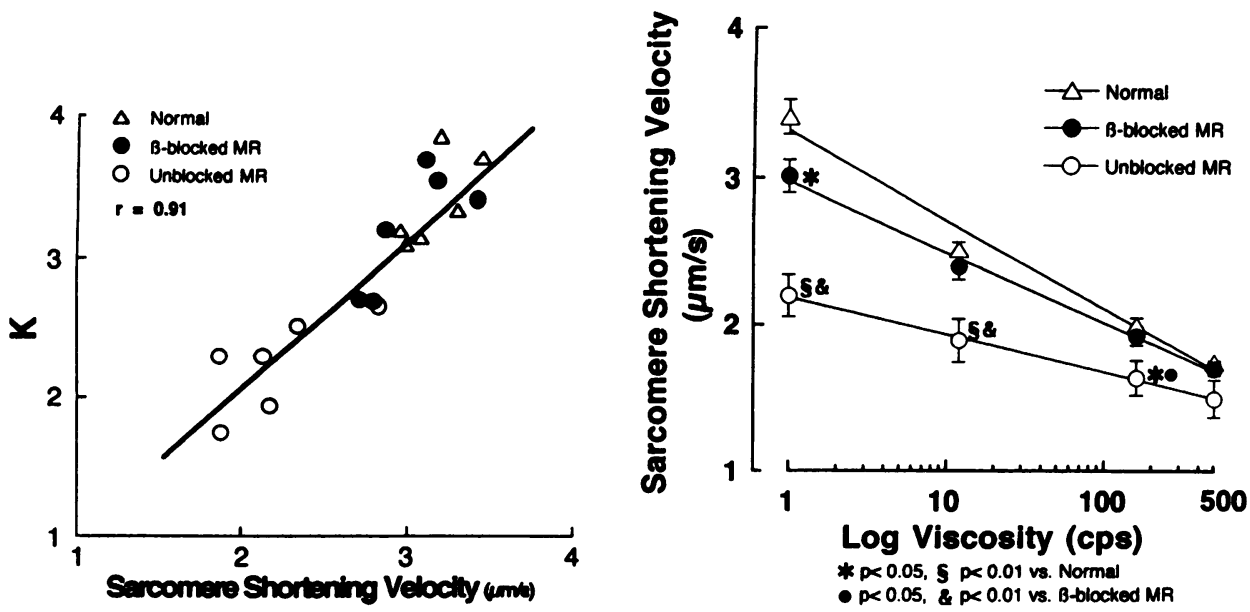

Figure 8. Left: An in vivo index of contractile function (end systolic stiffness, $K$ ) is plotted against an in vitro index of myocyte contractile function, sarcomere shortening velocity for normal dogs $(\Delta)$, the unblocked dogs with mitral regurgitation (MR) (O), and the $\beta$-blocked dogs (๑). An excellent correlation is demonstrated between in vivo and in vitro contractility. Further, the unblocked dogs demonstrate a reduction in both indexes while the $\beta$-blocked dogs were similar to normal. Right: The relationship between sarcomere shortening velocity and afterload (viscosity) is demonstrated for normal cells, for cells taken from the $\beta$-blocked MR dogs and for cells taken from the unblocked MR dogs. The velocity-viscosity relationship is similar in the $\beta$ blocked dogs to that of normals. In contrast, it is quite depressed in cells taken from the unblocked dogs. 
Table I. Myocardial and Cardiocyte Structure with Chronic Mitral Regurgitation in the Presence and Absence of $\beta$-Adrenergic Receptor Blockade

\begin{tabular}{|c|c|c|c|}
\hline Myocardium & Control & Chronic MR & $\begin{array}{c}\text { Chronic } \\
\mathrm{MR}+\beta \text { block }\end{array}$ \\
\hline \multicolumn{4}{|l|}{ Myocardium } \\
\hline Myocardial volume $\left(\mathrm{cm}^{3}\right)$ & $89 \pm 5$ & $117 \pm 12^{*}$ & $152 \pm 8^{* \ddagger}$ \\
\hline Myofibrillar volume $\left(\mathrm{cm}^{3}\right)$ & $57 \pm 3$ & $45 \pm 3^{*}$ & $87 \pm 5^{* \ddagger}$ \\
\hline Mitochondrial volume $\left(\mathrm{cm}^{3}\right)$ & $23 \pm 4$ & $28 \pm 3$ & $39 \pm 3^{* \ddagger}$ \\
\hline Capillary density $\left(\mathrm{n} / \mathrm{mm}^{2}\right)$ & $2387 \pm 174$ & $2256 \pm 370$ & $2670 \pm 290^{*}$ \\
\hline \multicolumn{4}{|l|}{ Cardiocytes } \\
\hline Cardiocyte length $(\mu m)$ & $189 \pm 5$ & $218 \pm 8^{*}$ & $217 \pm 7^{*}$ \\
\hline $\begin{array}{l}\text { Cardiocyte cross-sectional } \\
\text { diameter }(\mu m)\end{array}$ & $17.5 \pm 1.1$ & $18.5 \pm 1.9$ & $20.1 \pm 1.9^{*}$ \\
\hline $\begin{array}{l}\text { Computed cardiocyte } \\
\text { volume }\left(\mu \mathrm{m}^{3}\right) \times 10^{3}\end{array}$ & $34.6 \pm 0.8$ & $37.8 \pm 1.3$ & $38.6 \pm 2.2^{*}$ \\
\hline Percent myofibrils (\%) & $64 \pm 2$ & $39 \pm 2^{*}$ & $55 \pm 4^{* \pm}$ \\
\hline $\begin{array}{l}\text { Cardiocyte myofibril } \\
\quad \text { volume }\left(\mu \mathrm{m}^{3}\right) \times 10^{3}\end{array}$ & $21.7 \pm 0.7$ & $14.8 \pm 1.5^{*}$ & $21.3 \pm 1.5^{\ddagger}$ \\
\hline
\end{tabular}

MR, 3 mo of chronic mitral regurgitation; MR $+\beta$-block, MR with administration of $50 \mathrm{mg}$ of atenolol q.d. ${ }^{*} P<0.05$ vs. control; ${ }^{\ddagger} P$ $<0.05$ vs. MR.

not linked to improved $\beta$ receptor responsiveness. Further, the high correlation (Fig. 8) between cell function and ventricular function developed by groups of investigators blinded to each other's data suggests that much of the improvement in ventricular function was due to this mechanism. However, it is also possible that improved $\beta$ receptor responsiveness also played a role in improving in vivo measures of ventricular function. Thirdly, it appears that the improvement in intrinsic cardiocyte contractility was due to restoration of contractile elements in the cardiocytes. That is, myofibrillar content was increased by $41 \%$ in the $\beta$-blocked group compared to the unblocked group. Thus there were more contractile elements to generate force helping to explain the improvement in contractile function which we observed.

$\beta$-Adrenergic stimulation has long been considered one of the major compensatory mechanisms for contractile dysfunction arising from any cause $(16,55)$. Whereas it once was considered heresy to block the effects of this compensation in heart failure, several uncontrolled and controlled trials of gradually induced $\beta$ blockade in patients with congestive heart failure have demonstrated benefit from $\beta$ blockade $(18-21,56,57)$. Benefit was manifested both as improved longevity and by measurable increases in various parameters of left and right ventricular function.

The mechanisms by which gradually induced $\beta$ blockade produces this "paradoxical" benefit of improved left ventricular function were not clear. Previous studies have demonstrated that chronic $\beta$-adrenergic stimulation produces $\beta$ receptor down-regulation and weakens the response to $\beta$ stimulation $(22,23)$. There is solid evidence that $\beta$ receptor blockade leads to restoration of the $\beta$ receptor adenyl cyclase complex function (24). It is likely that this restoration in function allows for an enhanced response to episodically increased levels of $\beta$ receptor stimulation. However, restoration of $\beta$ receptor respon- siveness is probably not responsible for all of the observed increases in left ventricular function since the $\beta$ receptors are blocked by the $\beta$ blockade therapy and are thus rendered nonresponsive to tonic catecholamine levels. On the other hand in pheochromocytoma a naturally occurring model of $\beta$-adrenergic overstimulation, there is histologic damage which is reversed after removal of the tumor (58-60). Injury also occurs when isolated adult cardiocytes are exposed to high doses of catecholamines (17). These data suggest the chronic $\beta$ adrenergic stimulation reversibly damages the myocardium. Some of the damage which occurs may be secondary to the previously demonstrated calcium overload that develops due to $\beta$ receptor overstimulation (26). Our studies speak directly to the issue of myocardial injury. There was a loss of contractile elements and reduced contractile function associated with elevated catecholamines. After $\beta$ blockade contractile function improved. Our in vitro studies of cardiocytes isolated from chronically $\beta$-blocked mitral regurgitation ventricles showed improved contractile function. The improvement in contractile function occurred in connection with the restoration of contractile elements of the cell. Since the cells were studied in a catecholamine-free media after thorough washing, the $\beta$ receptors were presumably unoccupied. Thus, it is unlikely that the improvement in contractile function in the isolated cardiocytes was due to the effects of the chronic $\beta$ blockade on the $\beta$ receptor. Thus, it is likely that $\beta$ blockade was effective in these studies by "protecting" the myocardium from chronic $\beta$ adrenergic overstimulation. The exact mechanism of this protection remains to be elucidated. A third mechanism by which $\beta$ blockade could be effective (and which remains unexplored) is that of $\beta$ blockade-induced reduction in heart rate. Indeed, in this study, heart rate fell significantly in the $\beta$-blocked group. Reduced heart rate could restore contractility by reducing energy utilization, by reducing cellular injury due to calcium influx (61) or by restoring the ventricle to a more effective position on its force-frequency curve (62).

In the current study, $\beta$ blockade was associated with increased cardiac muscle mass. Increased myocardial mass must have been due at least in part to the restoration of myocardial contractile elements which we observed. Although catecholamines have been noted to be trophic in vitro in neonatal cardiocytes (63), catecholamines decrease protein synthesis in adult cardiocytes (17). We suspect that in our in vivo model $\beta$ blockade permitted the increase in left ventricular mass by allowing load-induced cardiac hypertrophy to occur under protection from catecholamine toxicity.

Limitations. In this study we did not examine $\beta$ receptor function. Thus, it is entirely possible and in fact likely that $\beta$ receptor up-regulation and improvement in responsiveness to $\beta$ receptor stimulation played some role in the improvement in the contractile function that we found in vivo. However, our correlation data suggest that much of the improvement in contractile function which we observed can be explained by improvement of contractility of the cardiocytes themselves which occurred in the absence of $\beta$ stimulation. This in turn was associated with the restoration of contractile elements suggesting that was a major mechanism of improvement seen in this study.

Obviously in this longitudinal study, we could not weigh the hearts directly at each observation period without killing the animal. Thus our mass measurements had to be calculated 

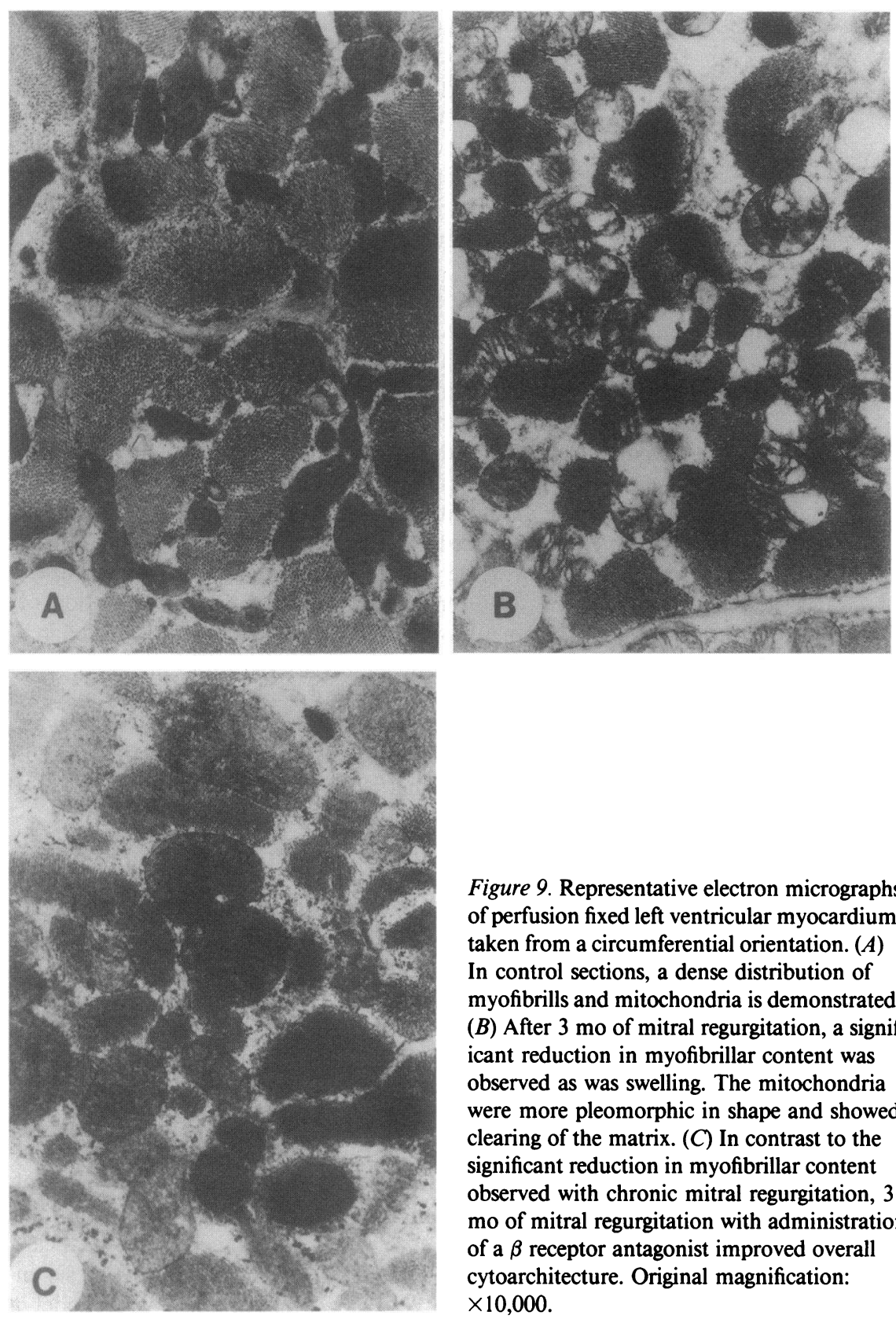

Figure 9. Representative electron micrographs of perfusion fixed left ventricular myocardium taken from a circumferential orientation. $(A)$ In control sections, a dense distribution of myofibrills and mitochondria is demonstrated. $(B)$ After 3 mo of mitral regurgitation, a significant reduction in myofibrillar content was observed as was swelling. The mitochondria were more pleomorphic in shape and showed clearing of the matrix. (C) In contrast to the significant reduction in myofibrillar content observed with chronic mitral regurgitation, 3 mo of mitral regurgitation with administration of a $\beta$ receptor antagonist improved overall cytoarchitecture. Original magnification: $\times 10,000$.

from angiographic data. However, in our hands such data have correlated extremely well with actual weight in the past (27).

Finally, our cell volumes were computed rather than directly measured by the Coulter Counter technique. However, in the past, the methods which we used have been in good agreement with the Coulter Counter technique (64).

Conclusions. We conclude that gradually induced $\beta$ blockade substantially improves the contractile dysfunction that occurs secondary to chronic experimental mitral regurgitation. Restoration of contractile function was based on restoration of contractile elements in isolated cardiocytes, which in turn led to improved ventricular function.

\section{Acknowledgments}

This work was supported in part by National Institutes of Health Grant NHLBI R01 HL38185 (Blase A. Carabello) and the Research Service of the Department of Veterans Affairs, Merit Review Grant (Blase A. Carabello).

\section{References}

1. Schuler, G., K. L. Peterson, A. Johnson, G. Francis, G. Dennish, J. Utley, P. O. Daily, W. Ashburn, and J. Ross Jr. 1979. Temporal response of left ventricular performance to mitral valve surgery. Circulation. 59:1218-1231.

2. Eckberg, D. L., J. H. Gault, R. L. Bouchard, J. S. Karliner, and J. Ross, Jr. 1973. Mechanics of left ventricular contraction in chronic severe mitral regurgitation. Circulation. 47:1252-1259.

3. Urabe, Y., D. L. Mann, R. L. Kent, K. Nakano, R. J. Tomanek, B. A. Carabello, and G. Cooper IV. 1992. Cellular and ventricular contractile dysfunction in experimental canine mitral regurgitation. Circ. Res. 70:131-147.

4. Mulieri, L. A., B. J. Leavitt, F. P. Ittleman, B. J. Martin, J. R. Haeberle, and N. R. Alpert. 1993. Forskolin reverses the force-frequency defect in left ventricular subepicardium (EPI) but not in papillary myocardium (PAP) in human mitra regurgitation heart failure. Circulation. 88:I-406. (Abstr.)

5. Grossman, W., D. Jones, and L. P. McLaurin. 1975. Wall stress and patterns of hypertrophy in the human left ventricle. J. Clin. Invest. 56:56-64. 
6. Corin, W. J., T. Murakami, E. S. Monrad, O. M. Hess, and H. P. Krayenbuehl. 1991. Left ventricular passive diastolic properties in chronic mitral regurgitation. Circulation. 83:797-807.

7. Wisenbaugh, T. 1988. Does normal pump function belie muscle dysfunction in patients with chronic severe mitral regurgitation? Circulation. 77:515525 .

8. Hochreiter, C., N. Niles, R. B. Devereux, P. Kligfield, and J. S. Borer. 1986. Mitral regurgitation: relationship of noninvasive descriptors of right and left ventricular performance to clinical and hemodynamic findings and to prognosis in medically and surgically treated patients. Circulation. 73:900-912.

9. Monrad, E. S., O. M. Hess, T. Murakami, H. Nonogi, W. J. Corin, and H. P. Krayenbuehl. 1988. Time course of regression of left ventricular hypertrophy after aortic valve replacement. Circulation. 77:1345-1355.

10. Wisenbaugh, T., J. F. Spann, and B. A. Carabello. 1984. Differences in myocardial performance and load between patients with similar amounts of chronic aortic versus chronic mitral regurgitation. J. Am. Coll. Cardiol. 3:916923.

11. Huber, D., J. Grimm, R. Koch, and H. P. Krayenbuehl. 1981. Determinants of ejection performance in aortic stenosis. Circulation. 64:126-134.

12. Dodge, H. T., J. W. Kennedy, and J. L. Petersen. 1973. Quantitative angiographic methods in the evaluation of valvular heart disease. Prog. Cardiovasc. Dis. 16:1-23.

13. Carabello, B. A., M. R. Zile, R. Tanaka, and G. Cooper IV. 1992. Left ventricular hypertrophy due to volume overload versus pressure overload. $A m$. J. Physiol. 263:H1137-H1144.

14. Ross, J. Jr., E. H. Sonnenblick, R. R. Taylor, H. M. Spotnitz, and J. W. Covell. 1971. Diastolic geometry and sarcomere lengths in the chronically dilated canine left ventricle. Circ. Res. 28:49-61.

15. Nagatsu, M., M. R. Zile, H. Tsutsui, P. G. Schmid, G. DeFreyte, G. Cooper IV, and B. A. Carabello. 1994. Native beta-adrenergic support for left ventricular dysfunction in experimental mitral regurgitation normalizes indexes of pump and contractile function. Circulation. 89:818-826.

16. Gaffney, T. E., and E. Braunwald. 1963. Importance of the adrenergic nervous system in the support of circulatory function in patients with congestive heart failure. Am. J. Med. 34:320-324.

17. Mann, D. L., R. L. Kent, B. Parsons, and G. Cooper IV. 1992. Adrenergic effects on the biology of the adult mammalian cardiocyte. Circulation. 85:790804.

18. Swedberg, K., F. Waagstein, A. Hjalmarson, and I. Wallentin. 1979. Prolongation of survival in congestive cardiomyopathy by beta-receptor blockade. Lancet. 1:1374-1376.

19. Eichhorn, E. J., J. B. Bedotto, C. R. Malloy, B. A. Hatfield, D. Deitchman, M. Brown, J. E. Willard, and P. A. Grayburn. 1990. Effect of $\beta$-adrenergic blockade on myocardial function and energetics in congestive heart failure. Improvements in hemodynamic, contractile, and diastolic performance with bucindolol. Circulation. 82:473-483.

20. Anderson, J. L., E. M. Gilbert, J. B. O'Connell, D. Renlund, F. Yanowitz, M. Murray, M. Roskelley, P. Mealey, K. Volkman, D. Deitchman, et al. 1991. Long-term ( 2 year) beneficial effects of beta-adrenergic blockade with bucindolol in patients with idiopathic dilated cardiomyopathy. J. Am. Coll. Cardiol 17:1373-1381.

21. Woodley, S. L., E. M. Gilbert, J. L. Anderson, J. B. O'Connell, D. Deitchman, F. G. Yanowitz, P. C. Mealey, K. Volkman, D. G. Renlund, R. Menlove, et al. 1991. $\beta$-blockade with bucindolol in heart failure caused by ischemic versus idiopathic dilated cardiomyopathy. Circulation. 84:2426-2441.

22. Bristow, M. R., R. Ginsburg, W. Minobe, R. S. Cubicciotti, W. S. Sageman, K. Lurie, M. E. Billingham, D. C. Harrison, and E. B. Stinson. 1982 Decreased catecholamine sensitivity and $\beta$-adrenergic-receptor density in failing human hearts. N. Engl. J. Med. 307:205-211.

23. Vatner, D. E., S. F. Vatner, J. Nejima, N. Uemura, E. E. Susanni, T. H. Hintze, and C. J. Homcy. 1989. Chronic norepinephrine elicits desensitization by uncoupling the beta-receptor. J. Clin. Invest. 84:1741-1748.

24. Heilbrunn, S. M., P. Shah, M. R. Bristow, H. A. Valantine, R. Ginsburg, and M. B. Fowler. 1989. Increased $\beta$-receptor density and improved hemodynamic response to catecholamine stimulation during long-term metoprolol therapy in heart failure from dilated cardiomyopathy. Circulation. 79:483-490.

25. Rona, G., C. I. Chappel, T. Balazs, and R. Gaudry. 1959. An infarct-like myocardial lesion and other toxic manifestations produced by isoproterenol in the rat. AMA Arch. Pathol. 67:443-455.

26. Fleckenstein, A., J. Janke, H. J. Doring, and O. Pachinger. 1973. Ca overload as the determinant factor in the production of catecholamine-induced myocardial lesions. Recent Adv. Study Card. Struct. Metab. 2:455-466.

27. Carabello, B. A., K. Nakano, W. Corin, R. Biederman, J. F. Spann, Jr. 1989. Left ventricular function in experimental volume overload hypertrophy. Am. J. Physiol. 256:H974-H981.

28. Nakano, K., M. M. Swindle, F.Spinale, K. Ishihara, S. Kanazawa, A. Smith, R. W. W. Biederman, L. Clamp, Y. Hamada, M. R. Zile, et al. 1991. Depressed contractile function due to canine mitral regurgitation improves after correction of the volume overload. J. Clin. Invest. 87:2077-2086.
29. Carabello, B. A., K. Nakano, K. Ishihara, S. Kanazawa; R. W. W. Biederman, and J. F. Spann, Jr. 1991. Coronary blood flow in dogs with contractile dysfunction due to experimental volume overload. Circulation. 83:1063-1075.

30. Hewett, K., M. J. Legato, P. Danilo, and R. B. Robinson. 1983. Isolated myocytes from adult canine left ventricle: $\mathrm{Ca}^{2+}$ tolerance, electrophysiology, and ultrastructure. Am. J. Physiol. 245:H830-H839.

31. Kent, R. L., D. L. Mann, Y. Urabe, R. Hisano, K. W. Hewett, M. Loughnane, and G. Cooper. 1989. The contractile function of isolated feline cardiocytes in response to viscous loading. Am. J. Physiol. 257:H1717-H1727.

32. Nakano, K., M. Sugawara, K. Ishihara, S. Kanazawa, W. J. Corin, S. Denslow, R. W. W. Biederman, and B. A. Carabello. 1990. Myocardial stiffness derived from end-systolic wall stress and the logarithm of the reciprocal of wal thickness: A contractility index independent of ventricular size. Circulation. 82:1352-1361.

33. Corin, W. J., M. M. Swindle, J. F. Spann, Jr., K. Nakano, M. Frankis, R. W. W. Biederman, A. Smith, A. Taylor, and B. A. Carabello. 1988. The mechanism of decreased forward stroke volume in children and swine with ventricular septal defect and failure to thrive. J. Clin. Invest. 82:544-551.

34. Suga, H., R. Hisano, Y. Goto, and O. Yamada. 1984. Normalization of end-systolic pressure-volume relation and Emax of different sized hearts. Jpn. Circ. J. 48:136-143.

35. Belcher, P., L. E. Boerboom, and G. N. Olinger. 1985. Standardization of end-systolic pressure-volume relation in the dog. Am. J. Physiol. 249:H547H553.

36. Krahwinkel, D. J. Jr., D. C. Sawyer, G. E. Eyster, and G. Bender G. 1975. Cardiopulmonary effects of fentanyl-droperidol, nitrous oxide, and atropine sulfate in dogs. Am. J. Vet. Res. 36:1211-1219.

37. Kleaveland, J. P., W. G. Kussmaul, T. Vinciguerra, R. Diters, and B. A Carabello. 1988. Volume overload hypertrophy in a closed-chest model of mitral regurgitation. Am. J. Physiol. 254:H1034-H1041.

38. Bristow, M. R., R. E. Hershberger, J. D. Port, W. Minobe, and R. Rasmussen. 1989. Beta 1- and beta 2-adrenergic receptor-mediated adenylate cyclase stimulation in nonfailing and failing human ventricular myocardium. Mol. Pharmacol. 35:295-303

39. Peuler, J. D., and G. A. Johnson. 1977. Simultaneous single isotope radioenzymatic assay of plasma norepinephrine, epinephrine and dopamine. Life Sci. 21:625-636

40. Krueger, J. W., D. Forletti, and B. A. Wittenberg. 1980. Uniform sarcomere shortening behavior in isolated cardiac muscle cells. J. Gen. Physiol. 76:587-607.

41. Wussling, M., W. Schenk, and B. Nilius. 1987. A study of dynamic properties in isolated myocardial cells by the laser diffraction method. J. Mol. Cell. Cardiol. 19:897-907.

42. Pollard, T. D. 1982. A falling ball apparatus to measure filament crosslinking. Methods Cell. Biol. 24:301-311.

43. Edman, K. A., and J. C. Hwang. 1977. The force-velocity relationship in vertebrate muscle fibres at varied tonicity of the extracellular medium. J. Physiol. (Lond.). 269:255-272.

44. Wildenthal, K., C. L. Skelton, and H. N. Coleman. 1969. Cardiac muscle mechanics in hyperosmotic solutions. Am. J. Physiol. 217:302-306.

45. Roos, K. P. 1986. Length, width, and volume changes in osmotically stressed myocytes. Am. J. Physiol. 251:H1373-H1378.

46. Spinale, F. G., J. L. Zellner, M. Tomita, F. A. Crawford, and M. R. Zile. 1991. Relation between ventricular and myocyte remodeling with the development and regression of supraventricular tachycardia-induced cardiomyopathy Circ. Res. 69:1058-1067.

47. Spinale, F. G., F. A. Crawford, Jr., K. W. Hewett, and B. A. Carabello. 1991. Ventricular failure and cellular remodeling with chronic supraventricula tachycardia. J. Thorac. Cardiovasc. Surg. 102:874-882.

48. Hansen-Smith, F. M., L. Watson, and G. R. Joswiak. 1989. Postnatal changes in capillary density of rat sternomastoid muscle. Am. J. Physiol. 257:H344-H347.

49. Spinale, F. G., R. C. Grine, G. E. Tempel, F. A. Crawford, and M. R. Zile 1992. Alterations in the myocardial capillary vasculature accompany tachycardia induced cardiomyopathy. Bas. Res. Cardiol. 87:65-79.

50. Spinale, F. G., R. Tanaka, F. A. Crawford, and M. R. Zile. 1992. Changes in myocardial blood flow during development of and recovery from tachycardiainduced cardiomyopathy. Circulation. 85:717-729.

51. Mendez, J., and A. Keys. 1960. Density and composition of mammalian muscle. Metab. Clin. Exp. 9:184-188.

52. Bishop, S. P., S. Oparil, R. H. Reynolds, and J. L. Drummond. 1979. Regional myocyte size in normotensive and spontaneously hypertensive rats. Hypertension. 1:378-383.

53. Rackley, C. E., H. T. Dodge, Y. D. Coble, Jr., and R. E. Hay. 1964. A method for determining left ventricular mass in man. Circulation. 29:666-671.

54. Mirsky, I. 1969. Left ventricular stresses in the intact human heart. Biophys. J. 9:189-208.

55. Francis, G. S., C. Benedict, D. E. Johnstone, P. C. Kirlin, J. Nicklas, C. S. Liang, S. H. Kubo, E. Rudin-Toretsky, and S. Yusuf. 1990. Comparison of neuro- 
endocrine activation in patients with left ventricular dysfunction with and without congestive heart failure: a substudy of the Studies of Left Venticular Dysfunction (SOLVD). Circulation. 82:1724-1729.

56. Waagstein, F., K. Caidahl, I. Wallentin, C. H. Bergh, and A. Hjalmarson. 1989. Long-term $\beta$-blockade in dilated cardiomyopathy. Effects of short- and long-term metoprolol treatment followed by withdrawal and readministration of metoprolol. Circulation. 80:551-563.

57. Engelmeier, R. S., J. B. O'Connell, R. Walsh, N. Rad, P. J. Scanlon, and R. M. Gunnar. 1985. Improvement in symptoms and exercise tolerance by metoprolol in patients with dilated cardiomyopathy: a double-blind, randomized, placebo-controlled trial. Circulation. 72:536-546.

58. Schaffer, M. S., P. Zuberbuhler, G. Wilson, V. Rose, W. J. Duncan, and R. D. Rowe. 1981. Catecholamine cardiomyopathy: an unusual presentation of pheochromocytoma in children. J. Pediatr. 99:276-279.

59. Lam, J. B., C. Shub, and S. G. Sheps. 1985. Reversible dilatation of hypertrophied left ventricle in pheochromocytoma: serial two-dimensional echocardiographic observations. Am. Heart J. 109:613-615.
60. Imperato-McGinley, J., T. Gautier, K. Ehlers, M. A. Zullo, D. S. Goldstein, and E. D. Vaughan. 1987. Reversibility of catecholamine-induced dilated cardiomyopathy in a child with a pheochromocytoma. N. Engl. J. Med. 316:793797.

61. Wier, W. G., and D. T. Yue. 1986. Intracellular calcium transients underlying the short-term force-interval relationship in ferret ventricular myocardium. J. Physiol. (Lond.). 376:507-530.

62. Mulieri, L. A., G. Hasenfuss, B. Leavitt, P. D. Allen, and N. R. Alpert. 1992. Altered myocardial force-frequency relation in human heart failure. Circulation. 85:1743-1750.

63. Simpson, P. 1983. Norepinephrine-stimulated hypertrophy of cultured rat myocardial cells is an alpha, adrenergic response. J. Clin. Invest. 72:732-738.

64. Gerdes, A. M., J. A. Moore, J. M. Hines, P. A. Kirkland, and S. P. Bishop. 1986. Regional differences in myocyte size in normal rate heart. Anat. Rec. 215:420-426. 